University of Nebraska - Lincoln

DigitalCommons@University of Nebraska - Lincoln

Investigations of the Ichthyofauna of

Nicaraguan Lakes

Papers in the Biological Sciences

1976

Pigments of a Color Polymorphism in a Cichlid Fish

\author{
Robert Webber \\ University of California - Berkeley \\ George W. Barlow \\ University of California - Berkeley \\ Alan H. Brush \\ University of Connecticut - Storrs
}

Follow this and additional works at: https://digitalcommons.unl.edu/ichthynicar

Part of the Aquaculture and Fisheries Commons

Webber, Robert; Barlow, George W.; and Brush, Alan H., "Pigments of a Color Polymorphism in a Cichlid Fish" (1976). Investigations of the Ichthyofauna of Nicaraguan Lakes. 29.

https://digitalcommons.unl.edu/ichthynicar/29

This Article is brought to you for free and open access by the Papers in the Biological Sciences at DigitalCommons@University of Nebraska - Lincoln. It has been accepted for inclusion in Investigations of the Ichthyofauna of Nicaraguan Lakes by an authorized administrator of DigitalCommons@University of Nebraska -

Lincoln. 
Comp. Biochem. Physiol., 1973 ,Vol. 44B, pp. 1127 to 1135. Pergamon Press. Printed in Great Britain

\title{
PIGMENTS OF A COLOR POLYMORPHISM IN A CICHLID FISH
}

\author{
ROBERT WEBBER, GEORGE WEBBER BARLOW and ALAN H. BRUSH* \\ Departments of Biochemistry and Zoology, and Museum of Vertebrate Zoology, University \\ of California, Berkeley, California 94720
}

(Received 28 fuly 1972)

\begin{abstract}
Cichlasoma citrinellum occurs as gray or gold morphs in lakes in Nicaragua. The gold morph is variable and individuals range from yellow to dark orange.

2. The pigments responsible for the carotenoid coloration are $\varepsilon$-carotene and canthaxanthin. The gray morph contains a carotenoid component and also heavy melanin deposits.

3. The carotenoids are dietary in origin, but their distribution and intensity is presumably under genetic control.

4. The relation of color morphs to the ecological and selective forces which might produce them is discussed.
\end{abstract}

\section{INTRODUCTION}

ThE occurRence of carotenoids in fishes has been widely documented. These pigments provide one of the major sources for the great diversity of colors that exists among this group of vertebrates (Goodwin, 1951; Fox, 1957). One aspect of the biology of pigments is the existence of color polymorphism or polychromatism. These color patterns are especially significant when different social, behavorial or ecological roles can be assigned to the morphs, or when their distribution is associated with some environmental gradient or phenomenon. Further, the biochemistry of the pigments is subject to analysis, and models may be built for the genetic control of their metabolism. Comparative studies may lead to generalizations regarding the evolution of carotenoid metabolism and control mechanisms responsible for their display. One impediment to the closer analysis of such problems is that the occurrence of colorful morphs is at a very low frequency in most species, even though the phenomenon occurs in widely unrelated fishes (e.g. blackbass, Allen \& Neil, 1953; minnows, Hubbs \& Miller, 1948; grunts, Hulquist, 1967; flatfish, McCormick \& Baldwin, 1952; groupers, Moe, 1963; eels, Pavesi, 1894; gars, Phillips, 1958; and sablefish, Phillips, 1952). The common goldfish and koi carp present abundant material; but these animals have been

* On leave from Biological Sciences Group, University of Connecticut, Storrs, Conn. 06268 . 
subjected to centuries of selection for their bright coloration, making evolutionary interpretations impossible.

Some indication of the nature and control of colors in fish is available. For example, Crozier (1967) studied the distribution and quantitative differences of carotenoids in seven closely related species of Sebastodes (= Sebastes), a marine rockfish. Both pigment quality and content were correlated with general body color and habitat preference of the species. It is generally known that red species of these predaceous scorpaenid fishes are taken at depths, while species with yellow or orange markings tend to occur in shallow water. Within species, the morphs of a sea horse, Hippocampus erectus, were analyzed chemically (Linton \& Hamilton, 1964). Color phase differences were due to variation in absolute and relative abundance of carotenoids coupled with the distribution of melanins. The functional role of the color morphs was not determined. A possible relationship between color and factors such as predator avoidance and concealment was investigated in fish by Sumner (1935). He concluded that the chromatophoric mechanisms involved in background matching had a high selective value. The maintenance of a high proportion of brilliantly colored morphs, then, must be done in the face of adverse selection from predators.

In Central America there are several large species of cichlid fishes that have occasional brilliantly colored morphs in various shades of yellow, orange, red or even white, and lack their species-typical melanin markings (Petenia splendida, Hubbs, 1935; Cichlasoma dovii, C. managuense and C. nicaraguense, Barlow, personal observation). In two abundant lake species in Nicaragua, C. labiatum and $C$. citrinellum, colorful morphs occur in large numbers, comprising up to 8-10 per cent of the adult populations in some lakes, being absent in others. Individual C. citrinellum even occur in piebald or mixed color patterns. A possibly parallel situation exists among some African lake cichlids, but the polychromatism there is largely limited to females (Greenwood, 1956; Fryer, 1961). Nothing is known about the pigments of any of these cichlid fishes.

C. citrinellum occurs as two morphs which we call gold and gray. The gold designation is a matter of convenience as this form varies from yellow through orange to red. All else being equal, golds behaviorally dominate the normal gray form. C. citrinellum breeds readily in captivity, providing an accessible source of fish. In order to understand the color bases of the morphs we determined the quantitative and qualitative nature of these differences. We report here the isolation and identification of the carotenoid pigments, variation in their concentration and observations on the associated melanins. This work provides an important basis for studies on the regulation of aggressive behavior in this species.

\section{MATERIALS AND METHODS}

The fish used in this study were bred in artificial ponds in the Life Sciences Building of the University of California, Berkeley. The ponds were supplied with free flowing, fresh water. The staple diet of ground beef heart and trout chow was supplemented with paprika, brine shrimp and commercial $\beta$-carotene. 
For purposes of analysis the skin and scales were removed from nine individual specimens, chopped into small pieces, weighed and extracted overnight at $4^{\circ} \mathrm{C}$ in acetone. Two subsequent extractions were made by heating the samples in acetone over a steam-bath for $5 \mathrm{~min}$. The pigments were transferred to $n$-hexane by first evaporating the crude extract, then washing with $n$-hexane three times in a separatory funnel. Usually two washings were adequate for total transfer. After the acetone extraction the skins were immersed overnight in petrol-ether, then heated on steam to extract any non-acetone soluble pigments. Insoluble pigments are discussed below.

The hexane mixtures were fractionated into components by thin-layer chromatography (TLC) on Eastman silica gel plates. Column chromatography of the crude extract on $\mathrm{MgO}-$-Celite $(1: 1)$ was found less effective on the small, individual samples. The samples were applied to the TLC plates with a No. 0 sable hair brush and developed in a standard chromatographic chamber in the solvent systems described by Johnson \& Brush (1972). The TLC apparatus was also used as a preparative technique. After standard development the individual bands were removed mechanically from the plate and the individual pigments eluded from the silica gel with a solution of $n$-hexane and $2-5 \%$ methanol. To estimate the relative distribution of pigments in the individual fish, mixtures of standardized concentration were spotted on a single plate and the spots recovered and the pigment concentration estimated spectrophotometrically.

To test for the presence of lipid esters, samples were hydrolyzed in $5 \%$ alkaline ethanol overnight at room temperature. Samples were transferred to $n$-hexane and the absorption spectra compared to that taken before treatment.

All visible absorption spectra were made on a Cary Model 14 recording spectrophotometer. The concentration of each pigment in $\mathrm{g} / 100 \mathrm{~g}$ sample was calculated by the relationship:

$$
\text { concentration }=\frac{\left(\mathrm{A} \lambda_{\max }\right)(\text { volume of fraction })(\text { density of hexane })(\text { volume of extract })}{E_{1 \mathrm{~cm}}^{1 \%} \text { (volume of extract used) }(\text { wet wt. sample) }} .
$$

Extinction coefficients of 2200 (canthaxanthin) and 2900 ( $\varepsilon$-carotene) were used (Foppen, 1971). Partition coefficients were determined by the method of Petracek \& Zechmeister (1956) and the types and numbers of polar side groups $\left(M_{50}\right)$ estimated by the method of Krinsky (1963). Infrared absorption spectra for structural studies on individual fractions were made on a Perkin-Elmer Model 257 Grating IR recording spectrophotometer. Spectra were taken in both $\mathrm{KBr}$ discs and $\mathrm{CHCl}_{3}$ solutions.

To test for the presence of melanins in the skin after acetone extraction, patches of skin were bathed in a solution of $10 \% \mathrm{H}_{2} \mathrm{O}_{2}$ and observed directly by light microscopy.

All chemicals were reagent grade and used without further processing.

\section{RESULTS}

Preliminary tests (Karrer \& Jucker, 1950) indicated that the acetone extracted pigments were carotenoids. On TLC two fractions were resolved in hexanemethanol $(1: 1)$, benzene-methanol $(98: 2$ or $25: 1$ ) and benzene-ethyl acetate $(2: 1)$. Four fractions were resolved in development in benzene-acetone $(98: 2)$. The latter solvent system was used regularly for isolation and identification of the pigments. The $R_{f}$ values, absorption maxima, partition coefficients and $M_{50}$ values for the pigment isolated from the crude extract are summarized in Table 1. 
Table 1 - Summary of SPECTRAL AND Chemical Data on Carotenoids of $C$. citrinellum

\begin{tabular}{|c|c|c|c|c|c|c|c|c|c|}
\hline & \multirow{2}{*}{$\begin{array}{c}R_{f} \\
\text { (benzene- } \\
\text { ethylacetate, } \\
2: 1 \text { ) }\end{array}$} & \multirow{2}{*}{$\begin{array}{c}R_{f} \\
\text { (benzene- } \\
\text { acetone, } \\
98: 2 \text { ) }\end{array}$} & \multicolumn{2}{|c|}{ Visible absorption } & \multicolumn{2}{|c|}{$\begin{array}{l}\text { I.r. spectra } \\
\text { (peaks) }\end{array}$} & \multirow{2}{*}{$\begin{array}{c}\text { Partition } \\
\text { coefficient } \\
\text { hexane } \\
(95 \% \text { MetOH })\end{array}$} & \multirow[b]{2}{*}{$M_{50}$} & \multirow[b]{2}{*}{ Melanin } \\
\hline & & & $\begin{array}{c}\text { In } n \text {-hexane } \\
(\lambda / \mu \mathrm{m})\end{array}$ & $\begin{array}{l}\text { Relative peak } \\
\text { intensity }\end{array}$ & $\begin{array}{l}2940 \\
1470\end{array}$ & $1740^{*}$ & & & \\
\hline \multirow[t]{2}{*}{ Gray morph } & 0.80 & $\begin{array}{l}0 \cdot 82 \\
0 \cdot 57\end{array}$ & $\begin{array}{l}468,440,416 \\
468,440,416\end{array}$ & $\begin{array}{l}0.93,1 \cdot 0,7 \cdot 1 \\
0.93,1 \cdot 0,7 \cdot 1\end{array}$ & $\begin{array}{l}+ \\
+\end{array}$ & $\begin{array}{l}- \\
-\end{array}$ & $\begin{array}{l}100: 0 \\
100: 0\end{array}$ & & \multirow{2}{*}{+} \\
\hline & 0.74 & $\begin{array}{l}0 \cdot 43 \\
0 \cdot 35\end{array}$ & $\begin{array}{l}467 \\
-\end{array}$ & $1 \cdot 0$ & + & + & $56: 44$ & $96 \cdot 4$ & \\
\hline \multirow[t]{2}{*}{ Yellow morph } & 0.80 & $\begin{array}{l}0 \cdot 84 \\
0 \cdot 56\end{array}$ & $\begin{array}{l}467,439,415 \\
467,439,415\end{array}$ & $\begin{array}{l}0.93,1 \cdot 0,0.69 \\
0.93,1 \cdot 0,0.69\end{array}$ & $\begin{array}{l}+ \\
+\end{array}$ & - & $\begin{array}{l}100: 0 \\
100: 0\end{array}$ & & \multirow{2}{*}{0} \\
\hline & 0.74 & $\begin{array}{l}0 \cdot 44 \\
0 \cdot 37\end{array}$ & $\begin{array}{l}467 \\
467\end{array}$ & $1 \cdot 0$ & + & + & $53: 47$ & $95 \cdot 8$ & \\
\hline \multirow[t]{2}{*}{ Orange morph } & $0 \cdot 80$ & $\begin{array}{l}0.84 \\
0.56\end{array}$ & $\begin{array}{l}469,440,416 \\
469,440,416\end{array}$ & $\begin{array}{l}0 \cdot 93,1 \cdot 0,0 \cdot 60 \\
0 \cdot 93,1 \cdot 0,0 \cdot 60\end{array}$ & + & - & $100: 0$ & & \multirow{2}{*}{0} \\
\hline & 0.74 & $\begin{array}{l}0 \cdot 44 \\
0 \cdot 37\end{array}$ & $\begin{array}{r}466 \\
464,361\end{array}$ & $\begin{array}{r}1 \cdot 0 \\
1 \cdot 0,0 \cdot 32\end{array}$ & $\begin{array}{l}+ \\
+\end{array}$ & $\begin{array}{l}+ \\
+\end{array}$ & $\begin{array}{l}53: 47 \\
53: 47\end{array}$ & $\begin{array}{l}95 \cdot 6 \\
95 \cdot 6\end{array}$ & \\
\hline Canthaxanthin & & & 468 & $1 \cdot 0$ & + & + & $\begin{aligned} 52 & : 48 \\
100 & : 0\end{aligned}$ & & \\
\hline$\varepsilon$-Carotene & & & $468,437,414$ & & & & & & \\
\hline
\end{tabular}

* Presence of i.r. peak at 1740 indicates keto-group. 


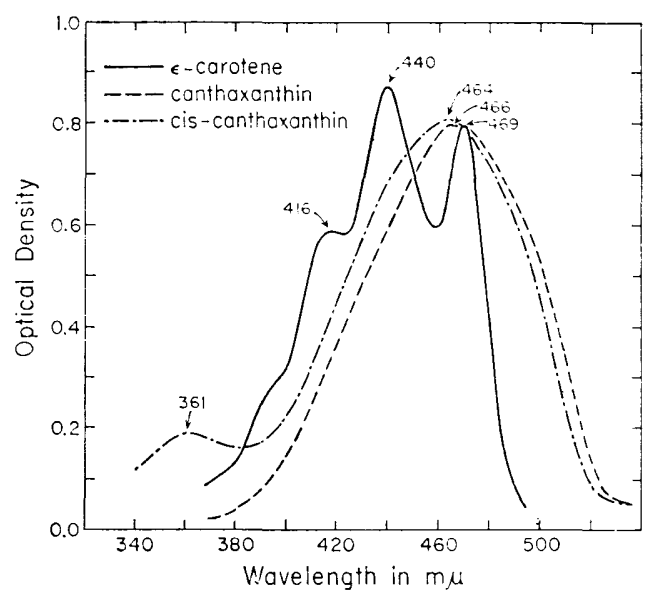

FIG. 1. Absorption spectra of carotenoid pigments isolated from $C$. citrinellum. The intense absorption in the $350-500 \mu \mathrm{M}$ range explains the yellow to red hue of the fish skin. The relationship between reflectance and transmission spectra has

been studied in avian plumage (Johnson \& Brush, 1972) but not fish skin.

\section{Identification}

Absorption spectra of the major chromatographic fractions indicated the presence of a carotene and a xanthophyll (Fig. 1). Infrared spectral data agreed, indicating the basic polyene structure with a keto group present in one fraction but not the other (Brügel, 1966). The partition coefficients, chromatographic behavior and relative polarity data were consistent with these observations. From these data, and co-chromatography, we have identified the major pigments in C. citrinellum as $\varepsilon$-carotene and canthaxanthin.

The minor bands produced in the benzene-acetone solvent system were indistinguishable from the associated major ones in i.r. spectra, partition coefficient and $\mathbf{M}_{50}$ values. In the visible spectra major absorption peaks were shifted slightly toward the shorter wavelengths; there was an additional minor peak at $361 \mu \mathrm{m}$ (Fig. 1). These spectral characteristics are generally associated with cis-isomers (Karrer \& Jucker, 1956; Isler, 1971). Isomerization has been reported previously for canthaxanthin (Cooney et al., 1966). On the basis of the spectral evidence, and apparent structural similarity, we conclude that the additional (e.g. minor) bands produced by the benzene-acetone $(98: 2)$ solvent system were cis-isomers of the major bands.

\section{Distribution}

Carotenoid pigments were present in the integument of all fish used in this study. The gray (normal) morphs also contained considerable amounts of melanin, as determined by direct observation of granules and bleaching with peroxide. Presumably the melanins served, to a great extent, to mask the carotenoids. Melanophores were not observed in the skin of the gold morph. 




FIG. 2. Concentration and distribution of carotenoid pigments in gold and gray morphs of $C$. citrinellum.

Color differences among individuals within the morphs were studied semiquantitatively on TLC. The distribution of pigments in five individuals is shown in Fig. 2. The coloration of individuals was determined by a mixture of the red and yellow pigments. Both gray individuals and yellow individuals of the gold morphs had approximately similar amounts of $\varepsilon$-carotene. In the more intensely colored orange individuals there was a slight increase in $\varepsilon$-carotene, but a dramatic increase in canthaxanthin. The gray morph varied widely in coloration when breeding. Their throats, eyes and the interspaces between bar markings on the flanks vary from pale yellow through canary yellow to orange and even red. The individuals used in this study were uniformly gray. In the gold morph there was excellent correspondence between the total carotenoid present and the overall color intensity.

\section{DISCUSSION}

The colors of $C$. citrinellum result from deposition of both melanin and carotenoid pigments. The difference between the gold and the normal gray morphs is due to the presence of masking melanin in gray fish. Within the gold morph variation in color from yellow through orange to red is due to an increasing concentration of a keto-carotene. We have identified the pigments as $\varepsilon$-carotene and canthaxanthin.

Canthaxanthin is distributed widely in animals. $\varepsilon$-Carotene, which is common in algae, was first reported from animals by Fox \& Hopkins (1965) and specifically from fish by Crozier \& Wilkie (1966). It may be distributed widely in fishes, occurring commonly as the $3,3^{\prime}$-dihydroxy derivative. It could be the source of reports of "lutein" or "taraxanthin-like" pigments in fishes (Crozier \& Wilkie, 1966). The absolute and relative concentration of these pigments may provide 
only a superficial explanation of the mechanisms involved in the production of color polymorphisms. Much of the display, in some species, obviously depends on short-term regulation of chromatophores (Fujii, 1967). The picture is further complicated in $C$. citrinellum in that the apparent color brightens and seems to shift from yellow toward orange with the onset of breeding. In the sibling species, C. labiatum, the bright morphs occur in shades of red, ranging from pink to dark red. At the present we have no data on their pigments.

Another consideration is the presence of carotenoids in the diet. In nature C. citrinellum is omnivorous and eats algae, snails, crustaceans and fishes. In captivity and on standard fare, the skin color fades slowly. The laboratory fish were given food that contained several potential carotenoids (see Materials and Methods) and which restored much of the color. One of the items, paprika, contained capsanthin. Another item, brine shrimp, is known to contain canthaxanthin plus traces of other carotenoids including pirardixanthin (Krinsky, 1965). Pirardixanthin was identified tentatively as 3,3'-dihydroxy- $\varepsilon$-carotene (Crozier \& Wilkie, 1966). In fishes generally, pigmentation of the flesh and skin can be affected by diet (for example, see Saito \& Regier, 1971, for a specific case involving diets containing crustacean material). The quality, amounts and stability of stored pigments, plus the general effect of diet and background color were summarized by Fox (1957) for several species of euryhaline or marine fish.

It is not clear why different individuals in a population selectively deposit certain of the carotenoids in their diet. While the intensity of the color may change with diet, some $C$. citrinellum are clearly more yellow and others orange. Further color mixtures, such as orange around the eyes of white fish, appear to be heritable. Existing models for the control of plumage carotenoids in birds imply a genetic basis for the difference (Brush \& Seifried, 1968; Brush, 1970). Since all the fish in this study presumably had equal access to the food, a genetic role is not inconsistent with our observations.

It is difficult to explain the distribution of color polymorphisms in various animal groups, and fishes are no exception. Colorful exteriors tend to be more common in visual, diurnal animals such as birds than in nocturnal, secretive forms. Despite the fact that many fish are colorful, especially those species whose distribution is tropical shallow waters, the occurrence of color polymorphisms is relatively low. The only case where the selective role of the different morphs is even partly understood is the three-spined Stickleback (Gasterosteus aculeatus) (McPhail, 1969; Semler, 1971). Here the pigments and their potential control mechanisms have been described (Brush \& Reisman, 1965). Yet there is a considerable paucity of information on the chemical basis of polychromatisms, their genetic control and their ecological and evolutionary roles in fishes.

Acknowledgements-Dr. Allan C. Wilson, Department of Biochemistry, generously provided laboratory space and supplies. This work was supported in part by National Science Foundation Grant No. GB 32192X to G. W. Barlow and a National Institutes of Health Special Fellowship to Alan H. Brush. 


\section{REFERENCES}

Allen E. R. \& NeIl N. T. (1953) A xanthic largemouth bass (Micropterus) from Florida. Copeia 1953, 116-117.

BRÜGEL W. (1962) An Introduction to Infrared Spectroscopy. Wiley, New York.

Brush A. H. (1970) Pigments in hybrid, variant and melanic tanagers. Comp. Biochem. Physiol. 36, 785-793.

BRUSH A. H. \& REISMAN H. M. (1965) The carotenoid pigments in the three-spined stickleback, Gasterosteus aculeatus. Comp. Biochem. Physiol. 14, 121-125.

Brush A. H. \& SEIFried H. (1968) Pigmentation and feather structure in genetic variants of the Gouldian finch, Poephila gouldiae. Auk 85, 416-430.

Cooney J. J., Markes H. W. \& SMith A. M. (1966) Isolation and identification of canthaxanthin from Micrococcus roseus. F. Bact. 92, 342-345.

Crozier G. F. (1967) Carotenoids of seven species of Sebastodes. Comp. Biochem. Physiol. 23, 179-184.

Crozier G. F. \& Wilkie D. W. (1966) Occurrence of a dihydroxy $\varepsilon$-carotenoid in a fish. Comp. Biochem. Physiol. 18, 801-804.

Foppen F. H. (1971) Tables for the identification of carotenoid pigments. Chromat. Rev. 14, 133-299.

Fox D. L. (1953) Animal Biochromes and Structural Colors. Cambridge University Press.

Fox D. L. (1957) The pigments of fish. In Physiology of Fishes (Edited by Brown M. E.), Vol. 2. Academic Press, New York.

Fox D. L. \& Hopkins T. S. (1965) Exceptional carotenoid metabolism in the Andean flamingo. Nature Lond. 206, 301-302.

FRYER G. (1961) Observations on the biology of the cichlid fish Tilapia variabilis Boulenger in the northern waters of Lake Victoria (East Africa). Rev. zool. Bot. Afr. 64, 1-33.

FujII R. (1969) Chromatophores and pigments. In Fish Physiology (Edited by HoAr W. S. \& Randall D. J.). Academic Press, New York.

Goodwin T. W. (1951) Carotenoids in fish. Biochem. Soc. Symp. 6, 63-82.

GreENwood P. H. (1956) The monotypic genera of cichlid fishes in Lake Victoria. Bull. Br. Mus. nat. hist. Zool. 3, 295-333.

Hubis C. L. (1935) Fresh-water fishes collected in British Honduras and Guatemala. Univ. Mich. Mus. Zool. Misc. Publ. 28, 5-22.

Hubbs C. L. \& Miller R. R. (1948) Two new, relict genera of cyprinid fishes from Nevada. Occ. Paps. Mus. zool. Univ. Mich., 507, 1-30.

Hulquist R. G. (1967) First recorded xanthic sargo, Anisotremus davidsonii Steindachner from the Salton Sea, California. Calif. Fish and Game 53, 292-293.

IsLER O. (Editor) (1971) Carotenoids. Birkhauser Verlag, Basel.

Johnson N. K. \& Brush A. H. (1972) Analyses of polymorphism in the sooty-capped bush tanager. Syst. Zool. 21, 245-262.

Karrer P. \& Jucker E. (1950) Carotenoids. Elsevier, New York.

KRINSKY N. I. (1963) A relationship between partition coefficients of carotenoids and their functional groups. Analyt. Biochem. 6, 293-302.

Krinsky N. I. (1965) The carotenoids of the brine shrimp, Artemia salina. Comp. Biochem. Physiol. 16, 181-187.

Linton J. R. \& Hamilton R. D. (1964) Carotenoids of the spotted sea horse, Hippocampus erectus Perry. Comp. Biochem. Physiol. 12, 341-346.

McCormick R. B. \& Baldwin W. J. (1952) Golden dover sole taken at Eureka. Calif. Fish and Game 38, 134.

McPhail J. D. (1969) Predation and the evolution of a stickleback (Gasterosteus). F. Fish Res. Bd Can. 26, 3183-3207.

Moe M. A., JR. (1963) Partial albinism in a xanthic specimen of Epinephelus morio (Valenciennes) from the Gulf of Mexico. Copeia 1963, 703. 
Pavesi P. (1894) Curioso metacromatismo in Auguilla. Rendic. Istit. Lomb. Milano 2, Ser. 27, 688-692.

Petracek F. J. \& Zechmeister L. (1956) Determination of partition coefficients of carotenoids as a tool in pigment analysis. Analyt. Chem. 28, 1484-1485.

Phillips C. (1958) An unusually colored garfish, Lepisosteus platyrhincus. Copeia 1958, 331.

Phillips J. B. (1952) Yellow sablefish (black cod) taken in Monterey Bay. Calif. Fish and Game 38, 437-438.

Saito A. \& Regier L. W. (1971) Pigmentation of brook trout (Salvelinus frontatis) by feeding dried crustacean wastes. F. Fish Res. Bd Can. 28, 509-512.

SELMER D. E. (1971) Some aspects of adaptation in a polymorphism for breeding colours in the threespine stickleback (Gasterosteus aculeatus). F. Zool. Lond. 165, 291-302.

SumNer F. B. (1935) Studies of protective color change-III. Experiments with fishes both as predator and prey. PNAS 21, 345-353.

Key Word Index-Cichlasoma citrinellum; carotenoids; $\varepsilon$-carotene; canthaxanthin; ecological coloration. 